\title{
Clinical profile and angiographic findings among patients with atrial fibrillation presenting for selective coronary angiography
}

\author{
Wael Elabbassi ${ }^{1^{*}}$, Mohammed Andaleeb Chowdhury ${ }^{2}$, Brano Liska $^{3}$, Robert Hatala ${ }^{4}$ \\ ${ }^{1}$ Al Qassimi Hospital, Ministry of Health, Sharjah, United Arab Emirates; *Corresponding Author: welabbassi@yahoo.com \\ ${ }^{2}$ University of Toledo, Toledo, USA; anda_batagol@hotmail.com \\ ${ }^{3}$ National Institute for Heart and Vascular Disease, Bratislava, Slovak Republic \\ ${ }^{4}$ Electrophysiology Unit, National Institute for Heart and Vascular Disease, Bratislava, Slovak Republic; \\ robert.hatala@nusch.sk
}

Received 28 October 2013; revised 28 November 2013; accepted 15 December 2013

Copyright (C) 2014 Wael Elabbassi et al. This is an open access article distributed under the Creative Commons Attribution License, which permits unrestricted use, distribution, and reproduction in any medium, provided the original work is properly cited. In accordance of the Creative Commons Attribution License all Copyrights (c) 2014 are reserved for SCIRP and the owner of the intellectual property Wael Elabbassi et al. All Copyright (C) 2014 are guarded by law and by SCIRP as a guardian.

\section{ABSTRACT}

Background: Coronary artery disease is the most common form of cardiovascular disease while Atrial fibrillation is the most common sustained arrhythmia. We set out to investigate the prevalence and clinical profile of patients with atrial fibrillation who present for selective coronary angiography and whether this has an effect on the angiogram findings and the treatment options offered to them. Methods and Results: This was a retrospectively collected database of 494 patients presenting for SCAG from 01.11.2010 to 30.11.2010 and 01.04.2010 to 30.04.2010. We collected and analyzed clinical characteristics of patients, their SCAG finding and modes of treatment offered up to discharge. $24.6 \%$ of patients had AF. They tended to be older, more commonly women, current or ex-smokers; presented with symptoms of atypical chest pain and were more likely to have a history of congestive heart failure or valvular heart disease. They had a longer hospital stay. Using CHADS-Vasc score, 83.6\% were moderate to high risk for CVA. At SCAG, they were more likely to have non-significant coronary artery disease, and hence were more likely to be treated conservatively. Conclusion: AF patients presenting for SCAG constitute a unique subset of patients who despite having a higher likelihood of non-significant coronary stenosis are still prone to suffering from poorly-understood and under-appreciated myo- cardial ischemia.

\section{KEYWORDS}

Atrial Fibrillation; Selective Coronary Angiography

\section{INTRODUCTION}

Each year, cardiovascular disease (CVD) causes over 4.3 million deaths in Europe overall including 1.9 million deaths inside the European Union (EU) [1]. Coronary artery disease is the most common form of cardiovascular disease with a prevalence of $6.9 \%$ and $6 \%$ among men and women [2]. Each year, two million Europeans die of CAD [3]. Selective coronary angiography is considered the golden standard for detection of coronary artery disease, especially among patients with acute coronary syndromes $[4,5]$. Atrial fibrillation (AF) is the most common sustained arrhythmia in humans affecting $1 \%$ - $2 \%$ of the population worldwide. Inside Europe and the United States, this translates to 3 and 6 million people respectively [6-9]. In the Renfrew survey [10], at a 20year follow-up, $89 \%$ of women and $66 \%$ of men who had atrial fibrillation also developed a cardiovascular event. Atrial fibrillation was an independent predictor of cardiovascular events among women (rate ratio $[R R]=3.0$; 95\% confidence interval [CI]: $2.1-4.2)$, and men (1.8; 95\% CI: 1.3 - 2.5).

We set out to investigate the prevalence of atrial fibrillation among patients presenting for SCAG at present days. We looked at their clinical profile and investigate 
whether atrial fibrillation was associated with their outcome of SCAG and how this affected the mode of treatment.

\section{METHODS}

This is a retrospectively collected database of patients presenting for SCAG to the National Institute for heart and vascular disease in Bratislava, Slovak Republic in the month of November, 2010 (01.11.2010-30.11.2010). To avoid random bias we randomly chose to collect data from another month of April (01.04.2010-30.04.2010). In November, 231 patients had SCAG and where included. In April, 263 patients presented for SCAG were enrolled.

Medical records of the patients was accessed and data about past medical and surgical history, baseline characteristics, indication for SCAG, results of SCAG, and the resulting form of therapy offered (Optimal Medical Therapy, Percutaneous Coronary Intervention, Coronary Artery Bypass and/or Valve replacement) where collected. Data about medications on discharge where also collected.

Atrial fibrillation (AF) was considered present by history, or if documented on Holter study or if it was present on ECG during hospital stay. Indications for SCAG where divided into seven categories: SCAG for a patient with established Acute Coronary Syndrome; SCAG for a patient with typical symptoms of angina; SCAG for a patient with atypical chest pain or shortness of breath or palpitations; SCAG for a patient with a Positive stress test; SCAG done for purposes of preoperative evaluation and possible treatment; SCAG done in context of workup of documented ventricular tachycardia or unexplained syncope.

Results from SCAG where recorded as "non-significant coronary disease”, "single vessel disease”, "two vessel disease”, and triple vessel disease, triple vessel disease with involvement of left main.

Mode of treatment was summarized into Optimized medical treatment (OMT), Coronary artery bypass graftingand valve replacement or repair, percutaneous coronary intervention treatment (PCI). Medications upon discharge where recorded into groups (ACE inhibitors, beta blockers, calcium channel blockers, statins, etc).

\section{STATISTICAL ANALYSIS}

All continuous variables are expressed as means +/$\mathrm{SD}$. The mean differences for continuous variables were compared using the Student $t$ test (two-tailed) or analysis of variance (in case of multiple comparisons). Categorical variables were compared using a chi-square statistic. A p value 0.05 was considered significant; where appropriate, 95\% confidence intervals were employed. Cox proportional hazards analysis was applied to determine the independent prognostic value of clinical, historical, and lab parameters. Selection of variables for consideration for entry was based on both univariate statistical significance and clinical judgment. The threshold for entry of variables into the final model was $\mathrm{p}=0.05$.

\section{RESULTS}

\subsection{Patient Characteristics}

One hundred and twenty two patients fulfilled our criteria for atrial fibrillation. This constituted $24.6 \%$ of study population. AF patients tended to be older, more commonly women, current or ex-smokers (Table 1); presented with symptoms of atypical chest pain or shortness of breath or palpitation; but also syncope or other documented arrhythmia (Figure 1). They were more likely to have history of congestive heart failure and valvular heart disease. They had a longer hospital stay. AF patients tended to have a higher prevalence of valvular heart disease and less wall motion abnormality (Figure 2). Using the CHADS-Vasc score, only 3.3\% were at low risk for stroke, $13.1 \%$ were at intermediate risk, and $83.6 \%$ were at moderate to high risk. At SCAG, they were more likely to have non-significant coronary disease (Figure 3), and more likely to be treated conservatively (OMT) (Figure 4). They were less often to be prescribed clopidogrel upon discharge; more often had warfarin, digoxin, calcium channel blockers and amiodarone prescribed.

There were no significant differences between the laboratory values or the hemodynamic parameters between the 2 groups.

\subsection{Univariate and Multivariate Analysis}

For all the patients, factors significantly associated with a finding of non-significant coronary disease at univariate analysis were: presence or history of atrial fibrillation, female gender, history of congestive heart failure, indication for SCAG as part of preoperative evaluation for valve surgery (Table 2).

At multivariate analysis; SCAG for preoperative evaluation, atrial fibrillation, female gender; were all positively associated with non-significant coronary artery disease findings at SCAG. On the other hand, the presence of diabetes, history of CAD, presenting with acute coronary syndrome; all were negatively associated with a finding of non-significant CAD (Table 3).

\section{DISCUSSION}

\subsection{Prevalence of AF}

Atrial fibrillation commonly accompanies other heart diseases [11]. Frequently, it presents as nonspecific complaints and symptoms. In a previous registry [12], the sensitivity and positive predictive value of patient-re- 
Tab le 1. Baseline characteristics of patients enrolled in this analysis by presence or absence of atrial fibrillation.

\begin{tabular}{|c|c|c|c|}
\hline & AF (122) & n-AF (372) & \multirow{2}{*}{ p value } \\
\hline & Mean $(95 \% \mathrm{CI})$ & Mean $(95 \% \mathrm{CI})$ & \\
\hline Age & $65.5(62-68.8)$ & $60(58-61.8)$ & 0.041 \\
\hline Males & $72(59 \%)$ & $266(71.5 \%)$ & 0.013 \\
\hline Females & $50(41 \%)$ & $106(28.5 \%)$ & \\
\hline $\begin{array}{c}\text { Length of } \\
\text { hospitalization }\end{array}$ & $5.2(4.1-6.4)$ & $4.5(3.9-4.1)$ & 0.006 \\
\hline BMI & $28.5(26.1-30.8)$ & $29.1(28.1-30.1)$ & 0.921 \\
\hline HTN & $99(81 \%)$ & $294(79 \%)$ & 0.698 \\
\hline $\mathrm{DM}$ & $36(29.5 \%)$ & $105(28.2 \%)$ & 0.818 \\
\hline Metabolic syndrome & $18(14.8 \%)$ & 48 (12.9\%) & 0.646 \\
\hline Dyslipidemia & $82(67.2 \%)$ & $255(68.5 \%)$ & 0.823 \\
\hline Known IHD & $36(29.5 \%)$ & $131(35.2 \%)$ & 0.271 \\
\hline Previous PCI & $7(5.7 \%)$ & $52(14 \%)$ & 0.015 \\
\hline Previous CABG/valve & $7(5.7 \%)$ & $27(7.3 \%)$ & 0.827 \\
\hline Previous vascular surgery & $1(0.8 \%)$ & $8(2.2 \%)$ & 0.516 \\
\hline Family history CAD & $1(0.8 \%)$ & $3(0.8 \%)$ & 1.000 \\
\hline HOCM & $1(0.3 \%)$ & $1(0.8 \%)$ & 0.433 \\
\hline Valvular heart disease & $32(26.2 \%)$ & $52(14 \%)$ & 0.003 \\
\hline $\begin{array}{l}\text { Other congenital } \\
\text { heart disease }\end{array}$ & $2(1.6 \%)$ & 7 (1.9\%) & 1.000 \\
\hline $\mathrm{CHF}$ & 47 (38.5\%) & $64(17.2 \%)$ & 0.001 \\
\hline $\begin{array}{l}\text { Rheumatic heart } \\
\text { disease }\end{array}$ & $11(9 \%)$ & 7 (1.9\%) & 0.001 \\
\hline Old PTMCA & $6(4.9 \%)$ & $1(0.3 \%)$ & 0.001 \\
\hline CVA & $3(2.5 \%)$ & $9(2.4 \%)$ & 1.000 \\
\hline Chronic renal & $11(9 \%)$ & $24(6.5 \%)$ & 0.318 \\
\hline Failure & & & \\
\hline Anemia & $10(8.2 \%)$ & 25 (6.7\%) & 0.548 \\
\hline COPD & $19(15.6 \%)$ & $83(22.3 \%)$ & 0.546 \\
\hline $\begin{array}{c}\text { Current or previous } \\
\text { smoker }\end{array}$ & 37 (30.3\%) & 147 (39.6\%) & 0.013 \\
\hline Cancer & $3(2.5 \%)$ & $14(3.8 \%)$ & 0.775 \\
\hline Other co-morbidities & $14(11.5 \%)$ & $44(11.8 \%)$ & 1.000 \\
\hline Echo performed & $118(96.7 \%)$ & 364 (97.8\%) & 0.502 \\
\hline Stress testing/CT angio & $6(4.7 \%)$ & 35 (9.1\%) & 0.093 \\
\hline LV Ejection Fraction & $49.5(43.1-55.8)$ & $52.1(49.5-54.6)$ & 0.660 \\
\hline $\begin{array}{c}\text { Moderate/severe } \\
\text { diastolic dysfunction }\end{array}$ & $26(21.3 \%)$ & $54(14.5 \%)$ & 0.287 \\
\hline $\begin{array}{c}\text { Moderate/severe } \\
\text { valvular abnormality }\end{array}$ & $43(35.2 \%)$ & $62(16.7 \%)$ & 0.001 \\
\hline Wall motion abnormality & $23(18.9 \%)$ & $144(38.7 \%)$ & 0.001 \\
\hline
\end{tabular}

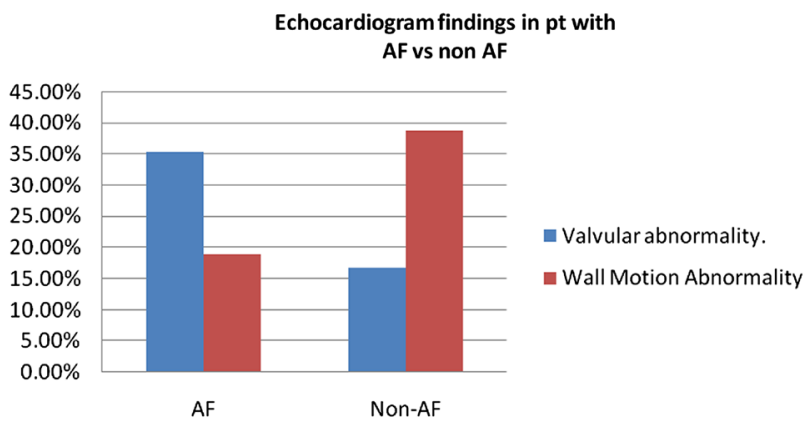

Figure 1. Indications of SCAG in patients presenting with AF vs non AF.

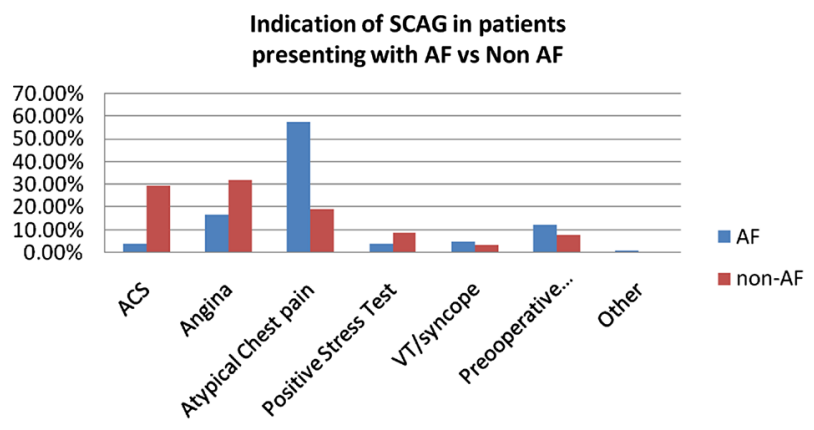

Figure 2. Echocardiographic findings in AF vs. non AF presenting for CAG. 


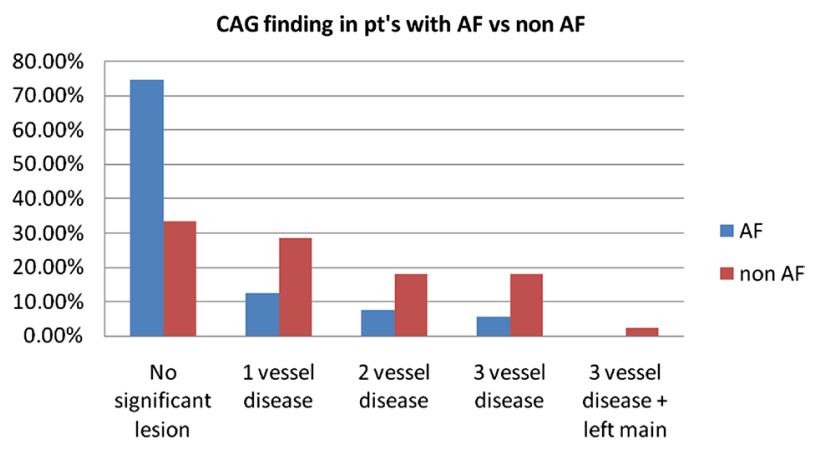

Figure 3. CAG findings in patients with AF vs. non AF.

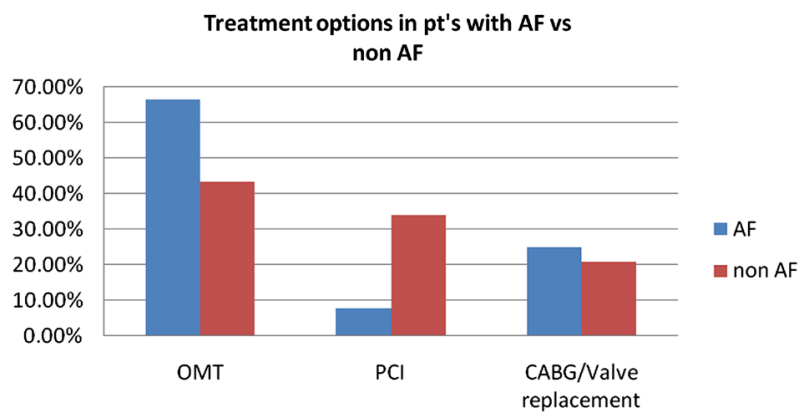

Figure 4. Treatment options offered to patients with AF vs non AF.

Table 2. Predictors for non-significant SCAG findings in univariate analysis in patients enrolled in this analysis by presence or absence of atrial fibrillation. CAD = coronary artery disease. $\mathrm{CHF}=$ congestive heart failure.

\begin{tabular}{cccc}
\hline & $\mathrm{AF}$ & $\mathrm{n}-\mathrm{AF}$ & $\mathrm{p}$ value \\
\hline Atrial fibrillation & $73.8 \%$ & $33.1 \%$ & 0.001 \\
Previously known & $16 \%$ & $46.8 \%$ & 0.001 \\
$\quad$ CAD & & & \\
Preoperative evaluation for & & & \\
$\quad$ Valve surgery & $70 \%$ & $36 \%$ & 0.001 \\
$\quad$ Female gender & $57 \%$ & $43 \%$ & 0.001 \\
$\quad$ Multiple other & & & \\
Co-morbid conditions & $60 \%$ & $40 \%$ & 0.004 \\
Diabetes Mellitus & $33 \%$ & $47 \%$ & 0.004 \\
$\quad$ CHF & $43 \%$ & $61 \%$ & 0.001 \\
Presentation with & & & \\
ACS/Angina & & & \\
\hline
\end{tabular}

Table 3. Multivariate regression analysis for predictors of nonsignificant SCAG in patients enrolled in this analysis by presence or absence of atrial fibrillation.

\begin{tabular}{ccc}
\hline & Odds ratio & p value \\
\hline Preoperative evaluation for & $4.1(2.6-6.5)$ & 0.005 \\
Valve surgery & $2.5(1.81-3.46)$ & 0.001 \\
Atrial fibrillation & $2.1(1.85-3.93)$ & 0.001 \\
$\begin{array}{c}\text { Female gender } \\
\text { Multiple other co-morbid } \\
\quad \text { conditions }\end{array}$ & $2.2(1.3-3.9)$ & 0.009 \\
$\begin{array}{c}\text { Diabetes Mellitus } \\
\text { Previously known }\end{array}$ & $0.6(0.38-0.85)$ & 0.012 \\
$\begin{array}{c}\text { CAD } \\
\text { Presentation with ACS/angina }\end{array}$ & $0.2(0.14-0.34)$ & 0.011 \\
\hline
\end{tabular}

ported symptoms for atrial fibrillation was merely $19 \%$ and $21 \%$, while $74 \%$ of patients who had episodes of paroxysmal AF documented by their pacemakers, yet had no complaints. Hence the real prevalence of AF is likely to be under appreciated [13]. The prevalence of atrial fibrillation among patients with proven coronary artery is thought to be low; $0.2 \%$ - 5\% [14-19]. AF Patients may present with chest pain, which can be accompanied by transient ischemic-type ST-segment changes with marginally elevated cardiac markers, thus mimicking symptoms of coronary artery disease [20]. Little is known about the prevalence of atrial fibrillation among specific subset of patients presenting for selective coronary angiography in modern era. In 1976, among 841 patients presenting for SCAG, AF was present in 5.3\% [15]. It was mostly associated with valvular heart disease and cardiomyopathy; while only 1 patient showed significant coronary artery disease. More recently in another survey in 1993, among 703 patients presenting for SCAG, 10.2\% had concomitant AF. Again these patients had more often valvular heart disease and cardiomyopathy, with nonsignificant CAD [18]. By far the largest group presenting for SCAG and investigated for AF was reported in 1999; out of 3220 patients, AF was present in 2.3\% [19]. They were more likely to have history of heart failure, triple vessel coronary artery disease and mitral valve insufficiency. In the AFFIRM Study [21], 38\% of their study population had Coronary artery disease. Another trial by Kralev et al. reported an overall incidence of coronary artery disease in patients presenting with AF to be $34 \%$ [22]. For the sake of comparison, we could not locate any previously published data documenting prevalence of AF among Slovakian patients presenting for SCAG. However, in this study we note a high prevalence of AF among SCAG patients (24.5\%). This may be attributed to a high prevalence of $\mathrm{CHF}$ and valvular heart disease among our patient population. Twenty percent of patients were indicated for SCAG as preoperative evaluation for valve surgery; $22.5 \%$ have a history of $\mathrm{CHF}$, and $28.5 \%$ were indicated for SCAG due to symptoms that could be related to congestive heart failure such as atypical chest pain, worsening exercise tolerance and increased shortness of breath.

\subsection{Factors Associated with AF}

Atrial Fibrillation patients where older $(p=0.041)$ and more likely female (41\% vs. $28.5 \%$ non-atrial fibrillation patients). This is contrast with the study group of Lokshyn et al [19], who were mostly men (71\%). The mean age of our AF patients was 65.5 years; which is in concordance with the findings from this other groups [19]. Generally it has been well described that the prevalence of AF doubles with each advancing decade of age, from 
$0.5 \%$ at age 50 - 59 years to almost $9 \%$ at age $80-89$ years [23]. AF patients had more often history of congestive heart failure and valvular heart disease, this is in agreement with most earlierreports [19,24,25]. Heart failure may contribute to the pathogenesis of atrial fibrillation, with electromechanical feedback and neurohumoral activation playing an important mediating role [26]. Only $51 \%$ of all patients presented with documented acute coronary syndrome and angina.

\subsection{AF and Coronary Ischemia}

It is conceivable that AF patients are over indicated for SCAG due to their nonspecific symptoms and the similar pool of risk factors to those with CAD (e.g. hypertension is a risk factor for both) [27]. The other possibility is that these patients suffer from ischemia despite the negative findings on SCAG $[28,29]$. Previous animal studies have documented a positive association between AF and myocardial ischemia. In dogs, artificially induced AF causes abnormal myocardial blood flow due to coronary vasoconstriction that is mediated by sympathetic activation of coronary alpha receptors [30]. In humans, AF has been known to reduce resting and hyperemic Myocardial Blood Flow (MBF), while coronary vascular resistance (CVR) increases [28]. Other studies indicated that acute AF causes a decline in diastolic coronary flow and promotes subendocardial ischemia [31]. Similar changes have been shown among AF patients with hypertrophic cardiomyopathy [32], and dilated cardiomyopathy [33], proving that AF may be a causative factor and not merely a bystander. AF patients are more likely to have positive SPECT finding for ischemia, yet have a lower yield of significant CAD by SCAG ( $15 \%$ for AF patients vs. $67 \%$ in n-AF; $p$ $=0.006$ ) [34].

This begs the question as to which is it the correct strategy for identifying Coronary Artery Disease in AF patients?

Furthermore; knowing that AF patients with false positive findings on scintigraphy still suffer a higher prevalence of cardiac death [35], should physicians become more aggressive at diagnosing and treating intermediate lesions found in AF patients (50\% - 70\% stenosis lesions)?

\section{CONCLUSION}

AF patients presenting for SCAG constitute a unique subset of patients who despite having a higher likelihood of non-significant coronary stenosis are still prone to suffering from poorly explained and under-appreciated myocardial ischemia. Newer pathways are needed for further risk stratification and treatment of this growing subset of patients.

\section{STUDY LIMITATIONS}

There are numerous sources of bias. First this is a retrospectively collected database of patients who elected for SCAG in only one tertiary institution in Europe. The definition of atrial fibrillation has been collected from chart documentations and it has not been possible verify it for these patients. Furthermore AF could not be stratified into various types (e.g. paroxysmal, persistent, and permanent). It is possible that the effect of AF is gradual i.e. more so for permanent $\mathrm{AF}$ patients versus patient with paroxysmal AF. This also needs further studying in prospectively collected data. Any conclusions drawn are clinical hypothesis generating and need further examination in a randomized trial setting; involving multiple centers. To date, scarce data have been published about this subject.

\section{REFERENCES}

[1] European Cardiovascular Disease Statistics (2005) British Heart Foundation Health Promotion Research Group.

[2] (2009) Heart disease and stroke statistics - 2010 update. Circulation, 121, e46-e215.

[3] Steg, G. (on behalf of the BEAUTIFUL Executive Committee) (2009) The CLARIFY registry: Management of stable coronary artery disease in clinical practice. Brochure for participating doctors.

[4] (2010) Guidelines on myocardial revascularization. The Task Force on Myocardial Revascularization of the European Society of Cardiology (ESC) and the European Association for Cardio-Thoracic Surgery (EACTS). European Heart Journal, 31, 2501-2555.

[5] ACCF/SCAI/STS/AATS/AHA/ASNC (2009) Appropriateness criteria for coronary revascularization. Journal of the American College of Cardiology, 530-553.

[6] Go, A.S., Hylek, E.M., Philips, K.A., Chang, Y.C., Henault, L.E., Selby, J.V. and Singer, D.E. (2001) Prevalence of diagnosed atrial fibrillation in adults: Nationalimplications for rhythm management and stroke prevention: The anticoagulation and risk factors in atrial fibrillation (ATRIA) study. JAMA, 285, 2370-2375. http://dx.doi.org/10.1001/jama.285.18.2370

[7] European Heart Rhythm Association, European Association for for Cardio-Thoracic Surgery, Camm, A.J., Kirchhof, P., Lip, G.Y.H., Schotten, U., Savelieva, I., Ernst, S., Van Gelder, I.C., Al-Attar, N., Hindricks, G., Prendergast, B., Heidbuchel, H., Alfieri, O., Angelini, A., Atar, D., Colonna, P., De Caterina, R., De Sutter, J., Goette, A., Gorenek, B., Heldal, M., Hohloser, S.H., Kolh, P., Le Heuzey, J.Y., Ponikowski, P. and Rutten, F.H. (2010) Guidelines for the management of atrialfibrillation: The task force for the management of atrial fibrillation. European Heart Journal, 31, 2369-2429. http://dx.doi.org/10.1093/eurheartj/ehq278

[8] Lloyd-Jones, D.M., Wang, T.J., Leip, E.P., Larson, M.G., Levy, D., Vasan, R.S., D’Agostino, R.B., Massaro, J.M., 
Beiser, A., Wolf, P.A. and Benjamin, E.J. (2004) Lifetime risk for development of atrial fibrillation: The framingham heart study. Circulation, 110, 1042-1046. http://dx.doi.org/10.1161/01.CIR.0000140263.20897.42

[9] Wattigney, W.A., Mensah, G.A. and Croft, J.B. (2003) Increasing trends in hospitalization for atrial fibrillation in the United States, 1985 through 1999: Implications for primary prevention. Circulation, 108, 711-716. http://dx.doi.org/10.1161/01.CIR.0000083722.42033.0A

[10] Stewart, S., Hart, C.L., Hole, D.J. and McMurray, J.J. (2002) A population-based study of the long-term risks associated with atrial fibrillation: 20-year follow-up of the Renfrew/Paisley study. American Journal of Medicine, 113, 359-364. http://dx.doi.org/10.1016/S0002-9343(02)01236-6

[11] Lévy, S. (1998) Epidemiology and classification of atrial fibrillation. Journal of Cardiovascular Electrophysiology, 9, S78-S82.

[12] Quirino, G., Giammaria, M., Corbucci, G., Pistelli, P., Turri, E., Mazza, A., Perucca, A., Checchinato, C., Dalmasso, M. and Barold, S.S. (2009) Diagnosis of paroxysmal atrial fibrillation in patients with implanted pacemakers: Relationship to symptoms and other variables. Pacing and Clinical Electrophysiology, 32, 91-98. http://dx.doi.org/10.1111/j.1540-8159.2009.02181.x

[13] Haigney, M.C. (2007) Reduced myocardial perfusion in atrial fibrillation: When the egg comes before the chicken. European Heart Journal, 28, 2181-2182. http://dx.doi.org/10.1093/eurheartj/ehm330

[14] Cheng, T.O. (1974) Coronary artery disease as an uncommon cause of atrial fibrillation. Clinical Research, 22, 268A.

[15] Haddad, A.H., Prchkov, V.K. and Dean, D.C. (1978) Chronic atrial fibrillation and coronary artery disease. Journal of Electrocardiology, 11, 67-69. http://dx.doi.org/10.1016/S0022-0736(78)80031-4

[16] Cameron, A., Schwartz, M.J., Kronmal, R.A. and Kosiuski, A.S. (1988) Prevalence and significance of atrial fibrillation in coronary artery disease (CASS Registry). American Journal of Cardiology, 61, 714-717. http://dx.doi.org/10.1016/0002-9149(88)91053-3

[17] Galrinho, A., Gomes, J.A., Antunes, E., Catarino, C., da Silva, N., Ferreira, R., Quininha, J. and Rato, J.A. (1993) Atrial fibrillation and coronary disease. Revista Portuguesa de Cardiologia, 12, 1037-1040.

[18] Shen, W., Feng, Y. and Gong, L. (1993) Atrial fibrillation and coronary artery disease. Chinese Medical Sciences Journal, 8, 177-179.

[19] Lokshyn, S., Mewis, C. and Kuhlkamp, V. (2000) Atrial fibrillation in coronary artery disease. International Journal of Cardiology, 72, 133-136. http://dx.doi.org/10.1016/S0167-5273(99)00180-1

[20] Kanjwal, K., Imran, N., Grubb, B. and Kanjwal, Y. (2008) Troponin elevation in patients with various tachycardias and normal epicardial coronaries. Indian Pacing and Electrophysiology Journal, 8, 172-174.

[21] AFFIRM Investigators (2002) Baseline characteristics of patients with atrial fibrillation: The AFFIRM study.
American Heart Journal, 143, 991-1001.

[22] Kralev, S., Schneider, K., Lang, S., Suselback, T. and Borggrefe, M. (2011) Incidence and severity of coronary artery disease in patients with atrial fibrillation undergoing first-time coronary angiography. PLoS One, 6, e24964. http://dx.doi.org/10.1371/journal.pone.0024964

[23] Kannel, W.B., Wolf, P.A., Benjamin, E.J. and Levy, D. (1998) Prevalence, incidence, prognosis and predisposing conditions for atrial fibrillation: Population based estimates. American Journal of Cardiology, 82, 2N-9N. http://dx.doi.org/10.1016/S0002-9149(98)00583-9

[24] Selzer, A. and Katayama, F. (1972) Mitral regurgitationClinical patterns, pathophysiology and natural history. Medicine, 51, 337-332.

[25] Ellis, L.B. and Ramirez, A. (1969) The clinical course of patients with severe rheumatic mitral insufficiency. American Heart Journal, 78, 406-418. http://dx.doi.org/10.1016/0002-8703(69)90047-7

[26] Van den Berg, M.P., Tuinenburg, A.E., Crijns, H.J., Van Gelder, I.C., Gosselink, A.T. and Lie, K.I. (1997) Heart Failure and atrial fibrillation: Current concepts and controversies. Heart, 77, 309-313.

[27] Velos o, H.H. and Costa Diniz, M. (2000) Are physicians recommending coronary angiographies more than necessary in atrial fibrillation? International Journal of Cardiology, 76, 85-86. http://dx.doi.org/10.1016/S0167-5273(00)00359-4

[28] Range, F.T., Schäfers, M., Acil, T., Schäfers, K.P., Kies, P., Paul, M., Hermann, S., Brisse, B., Breithardt, G., Schober, O. and Wichter, T. (2007) Impaired myocardial perfusion and perfusion reserve associated with increased coronary resistance in persistent idiopathic atrial fibrillation. $E u$ ropean Heart Journal, 28, 2223-2230. http://dx.doi.org/10.1093/eurheartj/ehm246

[29] Friedman, H.S., Scorza, J., McGuinn, R. and Shaughnessy, E. (1985) The effects of atrial fibrillation on myocardial blood flow and energetics. Experimental Biology and Medicine, 180, 1-8. http://dx.doi.org/10.3181/00379727-180-42135

[30] Ertl, G., Wichmann, J., Kaufmann, M. and Kochsiek, K. (1986) Alpha-receptor constriction induced by atrial fibrillation during maximal coronary dilatation. Basic Research in Cardiology, 81, 29-39.

http://dx.doi.org/10.1007/BF01907425

[31] Kochiadakis, G., Skalidis, E., Kalebubas, M., Igoumenidis, N.E., Chrysostomakis, S.I., Kanoupakis, E.M., Simantirakis, E.N. and Vardas, P.E. (2002) Effect of acute atrial fibrillation on phasic coronary blood flow pattern and flow reserve in humans. European Heart Journal, 23, 734-741. http://dx.doi.org/10.1053/euhj.2001.2894

[32] Sciagrà, R., Sotgia, B., Olivotto, I., Cecchi, F., Nistri, S., Camici, P.G. and Pupi, A. (2009) Relationship between atrial fibrillation and blunted hyperemic myocardial blood flow in patients with hypertrophic cardiomyopathy. Journal of Nuclear Cardiology, 16, 92-96. http://dx.doi.org/10.1007/s12350-008-9005-5

[33] Range, F.T., Paul, M., Schäfers, K.P., Acil, T., Kies, P., Hermann, S., Schober, O., Breithardt, G., Wichter, T. and Schäfers, M.A. (2009) Myocardial perfusion in nonische- 
mic dilated cardiomyopathy with and without atrial fibrillation. Journal of Nuclear Medicine, 50, 390-396. http://dx.doi.org/10.2967/jnumed.108.055665

[34] Smit, M.D., Tio, R.A., Slart, R.H., Zijlstra, F. and Van Gelder, I.C. (2010) Myocardial perfusion imaging does not adequately assess the risk of coronary artery disease in patients with atrial fibrillation. Europace, 12, 643-648. http://dx.doi.org/10.1093/europace/eup404
[35] Abidov, A., Hachamovitch, R., Rozanski, A., Hayes, S.W., Santos, M.M., Sciammarella, M.G., Cohen, I., Gerlach, J., Friedman, J.D., Germano, G. and Berman, D.S. (2004) Prognostic implications of atrial fibrillation in patients undergoing myocardial perfusion single-photon emission computed tomography. Journal of the American College of Cardiology, 44, 1062-1070.

http://dx.doi.org/10.1016/j.jacc.2004.05.076

\section{APPENDIX}

\section{ABBREVIATIONS}

\section{What's New?}

1) Prevalence of AF in patients presenting for Selective Coronary angiogram was $24.6 \%$.

2) AF was more prevalent among patients presenting for coronary angiogram with a history of congestive heart disease and valvular heart disease.

3) Majority of patients with AF had non-clinically significant coronary artery disease on coronary angiogram and required conservative medical management only.

4) Echocardiogram studies showed patients with $\mathrm{AF}$ to have more valvular heart disease and less regional wall motion abnormalities.

5) It is feasible that AF patients have myocardial ischemia; though not solely related to coronary stenosis but to previously documented, accentuated sympathetic tone causing enhanced coronary vasoconstriction and altered autonomic function; among other issues. This requires further prospective studying.

CVD: Cardiovascular Disease

EU: European Union

AF: Atrial Fibrillation

RR: Rate Ratio

CI: Confidence Interval

SCAG: Selective Coronary Angiography

OMT: Optimized Medical Treatment

PCI: Percutaneous Coronary Intervention

CAD: Coronary Artery Disease

MBF: Myocardial Blood Flow 